\title{
Analisis Pengaruh Keselamatan Kerja Dan Pelatihan Terhadap Kinerja Karyawan Pada PT Berca Schindler Lifts Project Alfa Tower Tangerang
}

\author{
Priehadi Dhasa Eka \\ Dosen Fakultas Ekonomi, Universitas Pamulang \\ Email : prihadi9967@gmail.com
}

\begin{abstract}
ABSTRAK
Tujuan penelitian untuk mengetahui keselamatan kerja dan pelatihan terhadap kinerja karyawan.

Metode Penelitian deskriptif dengan pendekatan asosiatif. Sample yang digunakan adalah proporsional random sampling dengan sampel sebanyak 56 responden dari 125 populasi. Menggunakan analisis regresi, analisis koefisien korelasi, analisis koefisien determinasi dan uji hipotesis.

Hasil penelitian bahwa keselamatan kerja berpengaruh positif dan signifikan terhadap kinerja karyawan sebesar $43.5 \%$ Uji hipotesis secara parsial diperoleh nilai $t$ hitung $>t$ tabel atau 2,392 $>1,297$, pengaruh positif dan signifikan secara parsial antara keselamatan kerja terhadap kinerja karyawan. Pelatihan berpengaruh positif dan signifikan terhadap kinerja karyawan sebesar 33.6\%. Uji hipotesis secara parsial diperoleh $\mathrm{t}$ hitung 2,9.16 $>\mathrm{t}$ tabel 1,297, pengaruh positif dan signifikan secara parsial. Nilai koefisien korelasi sebesar 0,520 artinya variabel bebas dan variabel terikat memiliki pengaruh yang sedang. Uji hipotesis simultan keselamatan kerja dan pelatihan positif dan signifikan terhadap kinerja kerja karyawan dengan koefisien determinasi sebesar 37,5\%, sedangkan sisanya sebesar $62,5 \%$ dipengaruhi faktor lain. Uji hipotesis diperoleh nilai $F$ hitung $>$ F tabel atau $(4,326>2,780)$. Pengaruh positif dan signifikan secara simultan antara Keselamatan Kerja dan Pelatihan terhadap Kinerja Karyawan pada PT. Bercha Schindler project Alfa Tower Tangerang
\end{abstract}

\section{Kata Kunci : Keselamatan Kerja, Pelatihan, Kinerja Karyawan}




\section{PENDAHULUAN}

PT. Berca Schindler Lifts (BSL) adalah perusahaan yang terkemuka dengan produk proses instalasi unit lift maupun escalator keselamatan dan kualitas demi menyediakan unti yang terbaik. Pembangunanya di awasi konsultan proyek (Jaya CM), mengawasi mulai dari design sampai selesai pekerjaan. maka konsultan terus menjalin komunikasi yang baik, meminimalisir kecelakaan yang terjadi dilapangan. Namun pada kenyataanya kinerja yang diihasilkan oleh SDM yang bekerja tidak sesuai yang diharapkan dikarenakan kurangnya kesadaran dari pekerja bahwa penggunaan APD (Alat Pelindng Diri) dan keselamatan kerja sangatlah penting.

Kinerja menurut Siswanto (dalam Muhammad Sandy, 2015:11) kinerja ialah prestasi yang dicapai oleh seorang dalam melaksanakan tugas dan pekerjaan yang diberikan kepadanya. Kinerja menurut (Tangkilisan, 2005 : 178) adalah suatu keadaan yang berkaitan dengan keberhasilan organisasi dalam menjalankan misi yang dimilikinya yang dapat diukur dari tingkat produktivitas, kualitas layanan, responsivitas, responsibilitas, dan akuntabilitas. Selanjutnya, definisi kinerja karyawan menurut A.A Anwar Prabu Mangkunegara (2000: 67) bahwa kinerja karyawan (prestasi kerja) adalah hasil kerja secara kualitas dan kuantitas yang dicapai oleh seseorang karyawan dalam melaksanakan tugasnya sesuai dengan tanggung jawab yang diberikan kepadanya.

Keselamatan adalah prioritas utama PT Berca Schindler Lifts.
Kami merancang sekaligus membuat lift dan escalator yang dilengkapi berbagai fitur serta mengutamakan keselamatan anda. PT. Berca Schindler Lifts pada Project Alfa Tower termasuk dalam department NI (New Installation) dimana bekerja sama dengan Departement lain untuk dapat menerapkan program pelatihan bagi setiap karyawan yang bekerja di PT. Berca Schindler Lifts agar kinerja terus meningkat.

Dari latar belakang yang diuraikan di atas, maka penulis mengidentifikasi masalah sebagai berikut :

1. Terdapat kecelakaan kerja dalam lingkungan project Alfa Tower Tangerang.

2. Adanya kelalaian dalam menggunakan Alat Pelindung Diri (APD).

3. Penyampaian bahasa materi dalam pelatihan karyawan masih kurang di pahami/dimengerti oleh karyawan.

4. Kurangnya kesadaran karyawan untuk hadir dalam pelatihan kerja yang diselenggarakan oleh PT. Bercha Schindler.

5. Kinerja karyawan masih belum optimal.

6. Masih kurangnya tanggung jawab dalam melakukan pekerjaan

Untuk memberikan arah pembahasan dan menghindari kebijaksanaan personal yang akan dibahas dalam penelitian ini, maka penulis perlu membatasi masalah yang menjadi kajian dalam pembahasan-pembahasan selanjutunya. Sesuai dengan judul skripsi ini maka penulis membatasi masalah pengaruh keselamatan kerja dan pelatihan kerja terhadap kinerja 
karyawan pada PT. Bercha Schindler Lifts Project Alfa Tower Tangerang.

1. Keselamatan kerja adalah system perlindungan diri terhadap segala kemungkinan yang dapat menyebabkan kecelakaan kerja

2. Pelatihan merupakan sebuah kegiatan yang dimana berutujan untuk mengasah kemampuan setiap karyawan agar menumbuhkan kinerja suatu karyawan semakin baik dan berkualitas.

3. Yang dimaksud kinerja dalam penelitian ini adalah suatu pencapaian seorang karyawan atas pekerjaan/tugas yang diberikan sesuai dengan waktuyang telah ditentukan.

4. Dilakukan penelitian di Project Alfa Tower yang beralamat di Jl. Jalur Sutera Barat Kav. 7-9 Kelurahan Penunggangan Timur Kecamatan Pinang, Kota Tangerang 15143.

\section{METODE PENELITIAN}

Penelitian ini dilaksanakan di PT. Berca Schindler Lifts di Project Alfa Tower yang beralamat di Jl. Jalur Sutera Barat. No. Kav.7-9, Panunggangan Tim., Kec. Pinang, Kota Tangerang, Banten 15143. Populasi adalah wilayah generalisasi yang terdiri dari objek atau subjek yang mempunyai kuantitas dan karakteristik tertentu yang ditetapkan oleh peneliti untuk dipelajari dan kemudian ditarik kesimpulannya.Secara umum populasi diartikan sebagai seluruh anggota kelompok yang ditentukan karakteristiknya dengan jelas, baik itu kelompok orang, objek atau kejadian. Dalam penelitian ini populasi yang diambil oleh penulis di PT. Berca Schindler Lifts di Project Alfa Tower adalah sebanyak 125 karyawan.

\section{HASIL PENELITIAN}

Tabel 4.1

Hasil Uji Validitas Berdasarkan Variabel Kinerja Karyawan (Y)

\begin{tabular}{|c|l|c|c|c|}
\hline No & \multicolumn{1}{|c|}{ Item Kuesioner } & $\begin{array}{c}\text { Chronbatch } \\
\text { Alpha }\end{array}$ & $\begin{array}{c}\text { Standar } \\
\text { Chronbatch } \\
\text { Alpha }\end{array}$ & Keputusan \\
\hline 1 & $\begin{array}{l}\text { Anda mampu menyelesaikan pekerjaan saya } \\
\text { sesuai dengan target yang sudah di tentukan }\end{array}$ & 0.381 & 0.300 & Valid \\
\hline 2 & Kualitas pekerjaan saya cukup memuaskan & 0.600 & 0.300 & Valid \\
\hline 3 & Anda selalu hadir tepat waktu & 0.324 & 0.300 & Valid \\
\hline 4 & $\begin{array}{l}\text { Anda mengerjakan tugas dan menyampaikan } \\
\text { hasil kerja dengan tepat waktu }\end{array}$ & 0.382 & 0.300 & Valid \\
\hline 5 & $\begin{array}{l}\text { Dengan tidak menunda pekerjaan berarti } \\
\text { Saya bekerja secara efektif }\end{array}$ & 0.544 & 0.300 & Valid \\
\hline 6 & $\begin{array}{l}\text { Anda berusaha bekerja secara efisien dengan } \\
\text { memanfaatkan waktu kerja yang tersedia }\end{array}$ & 0.631 & 0.300 & Valid \\
\hline 7 & $\begin{array}{l}\text { Anda tidak akan meninggalkan pekerjaan } \\
\text { anda sebelum anda yakin pekerjaan yang } \\
\text { anda lakukan benar }\end{array}$ & 0.508 & 0.300 & Valid \\
\hline 8 & $\begin{array}{l}\text { Anda bekerja berdasarkan job description } \\
\text { pekerjaan anda }\end{array}$ & 0.503 & 0.300 & Valid \\
\hline 9 & $\begin{array}{l}\text { Anda selalu menjaga hubungan kerja yang } \\
\text { baik dengan rekan kerja }\end{array}$ & 0.330 & 0.300 & Valid \\
\hline
\end{tabular}




\begin{tabular}{|c|l|c|c|c|}
\hline 10 & $\begin{array}{l}\text { Anda terbiasa bekerja sama satu dengan yang } \\
\text { lainnya dan tidak saling mengandalkan }\end{array}$ & 0.459 & 0.300 & Valid \\
\hline Rata-Rata & 0.466 & 0.300 & Valid \\
\hline
\end{tabular}

Sumber: Data Primer diolah.

Berdasarkan data tabel di atas, variabel kinerja karyawan (Y) diperoleh nilai Chronbatch Alpha 0,466 lebih besar dari 0,300, dengan demikian maka semua item kuesioner dinyatakan valid. Untuk itu kuesioner yang digunakan layak untuk diolah sebagai data penelitian.

\section{Tabel 4.2}

Hasil Uji Reliabilitas Variabel Independen dan Dependen

\begin{tabular}{|c|c|c|c|l|}
\hline No. & Variabel & $\begin{array}{c}\text { Coeficient } \\
\text { Alpha }\end{array}$ & $\begin{array}{c}\text { Standar } \\
\text { Chronbach } \\
\text { Alpha }\end{array}$ & Keputusan \\
\hline 1 & $\begin{array}{c}\text { Keselamatan } \\
\text { Kerja (X1) }\end{array}$ & 0.602 & 0.600 & Reliabel \\
\hline 2 & $\begin{array}{c}\text { Pelatihan } \\
\text { (X2) }\end{array}$ & 0.665 & 0.600 & Reliabel \\
\hline 3 & $\begin{array}{c}\text { Kinerja } \\
\text { Karyawan } \\
(Y)\end{array}$ & 0.653 & 0.600 & Reliabel \\
\hline
\end{tabular}

Sumber: Data Primer diolah.

Berdasarkan hasil pengujian pada tabel di atas, menunjukkan bahwa variabel Keselamatan Kerja $\left(X_{1}\right)$, Pelatihan $\left(X_{2}\right)$ dan Kinerja Karyawan (Y) dinyatakan reliabel, hal itu dibuktikan dengan masingmasing variabel memiliki nilai coeficien Alpha lebih besar dari Chronbath Alpha 0,600

Tabel 4.3

Hasil Uji Normalitas Dengan

Kolmogorov-Smirnov Test

\begin{tabular}{|c|c|c|c|c|c|c|}
\hline \multicolumn{6}{|c|}{ Tests of Normality } \\
\hline & \multicolumn{2}{|c|}{ Kolmogorov- } & & \\
Smirnov & & Shapiro-Wilk \\
\cline { 2 - 6 } & Statist & d & Sig & Statist & d & Sig \\
ic & f & . & ic & f & . \\
\hline
\end{tabular}

\begin{tabular}{|c|c|c|c|c|}
\hline \multirow{2}{*}{$\begin{array}{l}\text { Kinerja } \\
\text { Karyaw } \\
\operatorname{an}(Y)\end{array}$} & \multirow[t]{2}{*}{0.0876} & 0.20 & 0.973 & $|56| 0.23$ \\
\hline & & 0 & & 4 \\
\hline $\begin{array}{l}* \text {. This } \\
\text { signific }\end{array}$ & $\begin{array}{l}\text { lower } \\
\text { e. }\end{array}$ & & & \\
\hline
\end{tabular}

Sumber: Data Primer diolah.

Berdasarkan hasil pengujian pada tabel di atas, diperoleh nilai signifikansi $\alpha=0,234$ dimana nilai tersebut lebih besar dari nilai $\alpha=$ 0,050 atau $(0,234>0,050)$. Dengan demikian maka asumsi distribusi persamaan pada uji ini adalah normal.

\section{Pengujian Asumsi Klasik Uji Normalitas}

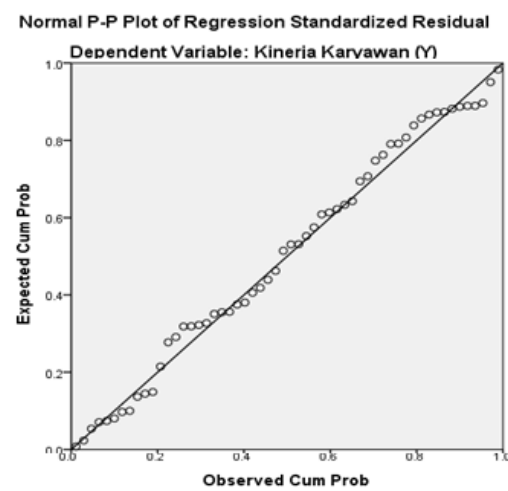

\section{Gambar 4.1}

P-Plot

Dapat dilihat bahwa grafik normal probability plot menunjukkan pola grafik yang normal. Hal ini terlihat dari titik yang menyebar disekitar garis diagonal dan penyebarannya mengikuti garis diagonal. Oleh karena ini dapat disimpulkan bahwa model regresi memenuhi asumsi normalitas. 
Tabel 4.4

Hasil Analisis Koefisien

Determinasi Secara Simultan

Antara Variabel Keselamatan

Kerja $\left(\mathrm{X}_{1}\right)$ dan Pelatihan (X2)

Terhadap Kinerja Karyawan (Y)

\begin{tabular}{|c|c|c|c|c|}
\hline \multicolumn{5}{|c|}{ Model Summary } \\
\hline $\begin{array}{c}\text { Mode } \\
1\end{array}$ & $\mathrm{R}$ & $\begin{array}{c}\mathrm{R} \\
\text { Squar } \\
\mathrm{e}\end{array}$ & $\begin{array}{c}\text { Adjuste } \\
\mathrm{d} \mathrm{R} \\
\text { Square }\end{array}$ & $\begin{array}{c}\text { Std. } \\
\text { Error of } \\
\text { the } \\
\text { Estimat } \\
\mathrm{e}\end{array}$ \\
\hline 1 & $\begin{array}{c}\mathrm{5} 20 \\
\mathrm{a}\end{array}$ &, 375 &, 108 & 3,372 \\
\hline
\end{tabular}

a. Predictors: (Constant), Pelatihan

(X2), Keselamatan Kerja (X1)

Sumber: Data Primer diolah.

Berdasarkan pada hasil pengujian pada tabel di atas, diperoleh nilai $R$-square sebesar 0,375 maka dapat disimpulkan bahwa variabel keselamatan kerja $\left(\mathrm{X}_{1}\right)$ dan pelatihan $(\mathrm{X} 2)$ berpengaruh terhadap variabel kinerja karyawan (Y) sebesar $37,5 \%$ sedangkan sisanya sebesar $62,5 \%$ dipengaruhi oleh faktor lain yang tidak dilakukan penelitian.

Tabel 4.5

Hasil Uji Hipotesis (Uji F) Secara

Simultan Antara Keselamatan

Kerja $\left(\mathrm{X}_{1}\right)$ dan Pelatihan (X2)

Terhadap Kinerja Karyawan (Y)

\begin{tabular}{|c|c|c|c|c|c|}
\hline Model & \multirow{2}{*}{$\begin{array}{c}\begin{array}{c}\text { Sum of } \\
\text { Squares }\end{array} \\
\\
98.371 \\
\end{array}$} & \multirow{2}{*}{ Df } & \multirow{2}{*}{$\begin{array}{c}\begin{array}{c}\text { Mean } \\
\text { Square }\end{array} \\
49.186 \\
\end{array}$} & \multirow{2}{*}{$\begin{array}{l}\mathrm{F} \\
4.326 \\
\end{array}$} & \multirow{2}{*}{$\begin{array}{l}\text { Sig. } \\
.001\end{array}$} \\
\hline 1 Regression & & & & & \\
\hline Residual & 602.611 & 53 & 11.370 & & \\
\hline Total & 700.982 & 55 & & & \\
\hline a. Dependent V & ble: Kinerj & Karyaw: & & & \\
\hline
\end{tabular}

Sumber :Data Primer di olah.

Berdasarkan pada hasil pengujian pada tabel di atas diperoleh nilai $F_{\text {hitung }}>\mathrm{F}$ tabel atau $(4,326>2,780)$, hal ini juga diperkuat dengan $\rho$ value $<$ Sig.0,05 atau $(0,001<0,05)$. Dengan demikian maka $\mathrm{H}_{0}$ ditolak dan $\mathrm{H}_{3}$ diterima, hal ini menunjukkan bahwa terdapat pengaruh positif dan signifikan secara simultan antara Keselamatan Kerja dan Pelatihan terhadap Kinerja Karyawan pada Keselamatan Kerja dan Pelatihan terhadap Kinerja Karyawan pada PT. Bercha Schindler project Alfa Tower.

\section{Pembahasan Hasil Penelitian}

\section{Pembahasan Deskriptif.}

Pembahasan deskriptif, dimaksudkan untuk eksplorasi dan klarifikasi mengenai fenomena atau kenyataan sosial, dengan jalan mendeskripsikan sejumlah variabel yang berkenaan dengan masalah yang diteliti.

a. Keadaan atau kriteria obyek yang diteliti berdasar pada variabel Keselamatan Kerja (X1).

Keselamatan kerja adalah kondisi keselamatan yang bebas dari resiko kecelakaan dan kerusakan di tempat kerja yang mencakup kondisi bangunan, kondisi mesin, peralatan keselamatan, kondisi pekerja.

Keadaan atau kriteria secara keseluruhan untuk kuesioner variabel Keselamatan kerja (X1) diperoleh rata-rata score 4.13 dengan kriteria baik. Dari 
keseluruhan pernyataan di atas, yang mendapatkan ratting score paling rendah adalah pernyataan nomor 3 dan 4 yaitu sirkulasi udara ditempat kerja membuat anda merasa nyaman dan perlengkapan pengaturan udara di area kerja sudah memadai dimana hanya mencapai score 4,09.

b. Keadaan atau kriteria obyek yang diteliti berdasar pada variabel Pelatihan $(\mathrm{X} 2)$.

Pelatihan adalah merupakan suatu usaha peningkatan pengetahuan dan kehalian seorang karyawan untuk mengerjakan suatu pekerjaan tertentu.

Keadaan atau kriteria secara keseluruhan untuk kuesioner variabel Pelatihan (X2) diperoleh rata-rata score 3.98 dengan kriteria baik. Dari keseluruhan pernyataan di atas, yang mendapatkan ratting score paling rendah adalah pernyataan nomor 7 yaitu Materi yang diberikan lengkap dan dapat dengan mudah di pahami dimana hanya mencapai score 3,95.

c. Keadaan atau kriteria obyek yang diteliti berdasar pada variabel Kinerja Karyawan (Y).

Kinerja Karyawan adalah hasil kerja secara kualitas dan kuantitas yang dicapai oleh seseorang pegawai dalam melaksanakan tugasnya sesuai dengan tanggung jawab yang diberikan kepadanya.

Keadaan atau kriteria secara keseluruhan jawaban responden responden untuk kuesioner variabel Kinerja Karyawan (Y) diperoleh ratarata score 4.53 dengan kriteria sangat baik. Dari keseluruhan pernyataan di atas, yang mendapatkan ratting score paling rendah adalah pernyataan nomor 2 yaitu Kualitas pekerjaan saya cukup memuaskan dimana hanya mencapai score 4,00.

\section{Pembahasan Verifikatif}

Pembahassan verifikatif dimaksudkan untuk membahas perihal pengaruh dan signifikansinya serta, pembahasan keterkaitan teori yang mendukung yang diselaraskan dengan hasil pengolahan data.

\section{a. Pengaruh Secara Parsial antara Keselamatan Kerja (X1) terhadap Kinerja Karyawan (Y).}

Terdapat pengaruh posistif dan signifikan secara parsial antara Keselamatan Kerja (X1) terhadap Kinerja Karyawan (Y). hal ini ditunjukan dengan nilai thitung Variabel Keselamatan Kerja (X1) terhadap Kinerja Karyawan (Y) sebesar thitung 2,392 > ttabel 1.297. atau Sig $0.000<0.05$ Maka Ho ditolak dan $\mathrm{Ha}$ diterima artinya terdapat pengaruh yang positif dan signifikan antara Keselamatan Kerja (X1) terhadap Kinerja Karyawan (Y).

Tingkat hubungan

Keselamatan Kerja (X1) terhadap Kinerja Karyawan (Y) sebesar 0.686 artinya Keselamatan Kerja (X1) 
memiliki tingkat hubungan yang kuat terhadap Kinerja Karyawan (Y). dan bahwa kemampuan Variabel Kinerja (Y) dipengaruhi oleh Variabel Kesleamatan Kerja (X1) sebesar $43.5 \%$ sedangkan $56.5 \%$ merupakan pengaruh dari variabel lain yang tidak di teliti dalam penelitian ini.

b. Pengaruh Secara Parsial antara Pelatihan (X2) terhadap Kinerja Karyawan (Y).

Terdapat pengaruh posistif dan signifikan secara parsial antara Pelatihan (X2) terhadap Kinerja Karyawan (Y). hal ini ditunjukan dengan nilai thitung Variabel Pelatihan (X2) terhadap Kinerja Karyawan (Y) sebesar thitung 2,913 > ttabel 1,297. atau Sig $0.000<0.05$ Maka Ho ditolak dan $\mathrm{Ha}$ diterima artinya terdapat pengaruh yang positif dan signifikan antara Budaya Organisasi (X2) terhadap Kinerja Karyawan (Y).

Tingkat hubungan Pelatihan (X2) terhadap Kinerja Karyawan (Y) sebesar 0,569 artinya Pelatihan (X2) memiliki tingkat hubungan yang Sedang terhadap Kinerja Karyawan (Y). dan bahwa kemampuan Variabel Kinerja (Y) dipengaruhi oleh Variabel Budaya Organisasi (X1) sebesar $31.2 \%$ sedangkan $68.8 \%$ merupakan pengaruh dari variabel lain yang tidak di teliti dalam penelitian ini.

c. Pengaruh Secara Simultan antara Keselamatan Kerja (X1), Pelatihan (X2) terhadap Kinerja Karyawan (Y).

Terdapat pengaruh secara simultan antara Keselamatan Kerja(X1), Pelatihan (X2) terhadap Kinerja Karyawan (Y). hal ini ditunjukan dengan nilai Fhitung 4,326 lebih besar dibandingkan dengan Ftabel 2,780, dan Sig. 0,001 lebih kecil dari alpha 5\% (0.05). hal ini mengindikasikan bahwa hasil penelitian menolak Ho dan menerima $\mathrm{Ha}$ dengan demikian secara serempak Keselamatan Kerja dan Pelatihan berpengaruh signifikan terhadap Kinerja Karyawan pada PT. Berca Schindler Lifts .

Dari hasil regresi linear berganda yang telah ditemukan adalah $\hat{\mathrm{Y}}=22.366+0.076 \mathrm{X} 1$ +0.408 X2 dimana konstanta sebesar 22.366 menyatakan bahwa tanpa Variabel Keselamatan Kerja (X1) dan Pelatihan (X2), besarnya nilai Kinerja Karyawan (Y) tetap terbentuk 22.366. kemudian Variabel Keselamatan Kerja (X1) berpengaruh positif terhadap terhadap Variabel Kinerja Karyawan (Y) dengan nilai koefisien sebesar 0.076 . yang artinya jika Variabel (X1) meningkat satu satuan, maka Kinerja Karyawan (Y) akan meningkat sebesar 0.076, dan Variabel Pelatihan (X2) berpengaruh positif terhadap terhadap Variabel Kinerja Karyawan (Y) dengan nilai koefisien sebesar 0.408. yang artinya jika Variabel Pelatihan (X2) meningkat satu satuan, 
maka Kinerja Karyawan (Y) akan meningkat sebesar 0.408 .

Nilai Adjustes R Square sebesar $\quad 0.435 \quad$ yang menunjukan bahwa variabel Kinerja Karyawan (Y) dipengaruhi oleh variabel Keselamatan Kerja (X1) dan variabel Pelatihan (X2) sebesar $43,5 \%$ dan sisanya sebesar $56,5 \%$ dipengaruhi oleh variable lain yang tidak diteliti.

\section{KESIMPULAN DAN SARAN}

\section{A. Kesimpulan}

1. Keselamatan Kerja (X1) berpengaruh positif dan signifikan terhadap Kinerja karyawan (Y) dengan nila koefisien korelasi sebesar 0,686 artinya kedua variabel memiliki pengaruh yang kuat dengan koefisien determinasi sebesar $43,5 \%$. Uji hipotesis diperoleh $\mathrm{t}$ hitung $>\mathrm{t}$ tabel atau $(2,392>1,297)$, hal ini diperkuat dengan probability signifikansi $0,000<0,05$, dengan demikian $\mathrm{HO}$ ditolak dan H1 diterima artinya terdapat pengaruh positif dan signifikan antara Keselamatan Kerja terhadap Kinerja Karyawan pada PT. Bercha Schindler project Alfa Tower.

2. Pelatihan (X2) berpengaruh positif dan signifikan terhadap Kinerja karyawan (Y) dengan nilai koefisien korelasi sebesar 0,569 artinya kedua memiliki pengaruh yang Sedang dengan koefisien determinasi sebesar $31,2 \%$. Uji hipotesis diperoleh $\mathrm{t}$ hitung > t tabel atau (2,913 > 1,297), hal ini diperkuat dengan probability signifikansi
$0,000<0,05$, dengan demikian $\mathrm{H} 0$ ditolak dan $\mathrm{H} 2$ diterima artinya terdapat pengaruh positif dan signifikan antara Peelatihan Kerja (X2) terhadap Kinerja Karyawan (Y) pada pada PT. Bercha Schindler project Alfa Tower.

3. Keselamatan Kerja (X1) dan Pelatihan (X2) berpengaruh positif dan signifikan terhadap Kinerja Karyawan (Y) dengan persamaan regresi $\mathrm{Y}=22,366$ $+0,076 \mathrm{X} 1+0,408 \mathrm{X} 2$. Nilai koefisien korelasi diperoleh sebesar 0,520 artinya variabel bebas dengan variabel terikat memiliki pengaruh yang sedang dengan koefisien determinasi atau pengaruh secara simultan sebesar $37,5 \%$ sedangkan sisanya sebesar $62,5 \%$ dipengaruhi faktor lain. Uji hipotesis diperoleh nilai $F$ hitung > F tabel atau (4,326 > 2,780), hal tersebut juga diperkuat dengan probability signifikansi $0,000<0,05$. Dengan demikian H0 ditolak dan H3 diterima. Artinya terdapat pengaruh positif dan signifikan secara simultan antara Keselamatan Kerja dan Pelatihan terhadap Kinerja karyawan pada PT. Bercha Schindler project Alfa Tower.

\section{B. Saran}

1. Variabel Keselamatan Kerja (X1) pernyataan yang paling lemah adalah sirkulasi udara ditempat kerja membuat anda merasa nyaman dan perlengkapan pengaturan udara di area kerja sudah memadai dimana hanya mencapai score 
sebesar 4,09. Untuk lebih baik lagi perusahaan harus menyediakan alat ventilator blower, dikarenakan fungsi dari ventilator blower/kipas ventilator ini dapat menghasilkan volume udara yang besar serta tekanan yang tinggi. Biasanya digunakan sebagai ventilasi udara di restoran, bengkel, terowongan, Lorong Gedung (vertical) pembuatan kapal, saluran pembuangan gas dan lain-lain. Dengan menggunakan alat ini sirkulasi udara di sekitar pekerjaan yang berdebu, berasap dapat segera di netralisir karna ventilator blower ini dirancang untuk menyuplai udara baru dan dapat mengeluarkan udara kotor dari suatu ruangan yang tertutup. Alat ini sangat di butuhkan mengingat sirkulasi di daerah pekerjaan yang dilakukan baik di shaft maupun ruangan yang minim ventilasi hanya mengandalkan lubang pintu-pintu untuk lift .

2. Variabel Pelatihan (X2), pernyataan yang paling lemah adalah materi yang diberikan lengkap dan dapat dengan mudah di pahami, dimana hanya mencapai score 3,95. Untuk lebih baik lagi perusahaan dalam pelatihannya agar memperbanyak menggunkan bahasa Indonesia atau dapat mengkombinasikanya, karna mungkin masih belum bisa menyesuaikan ataupun belum semua sempurna pengetahuan dalam Bahasa inggris, dan juga dapat menggunakan kata-kata istilah atau kalimat umum yang sering didengar di lingkungan.

3. Variabel Kinerja karyawan (Y), Kualitas pekerjaan saya cukup memuaskan dimana hanya mencapai score sebesar 4,00 . Untuk lebih baik lagi perusahaan harus bisa membangkitkan semangat kerja karyawan dan menjamin keselamatan setiap karyawannya pada saat menunaikan kewajibanya sebagai pekerja, dan karyawan merasa terlindungi dengan adanya perhatian keselamatan dalam bekerja di perusahaan, sehingga pekerjaan yang dilakukan karyawan menjadi lebih terfokus/tidak khawatir karna perusahaan ada di tengah-tengah karyawan, dan pekerjaan yang di selesaikannya merasa puas baik dari sisi perusahaan maupun sisi karyawan.

\section{DAFTAR PUSTAKA}

Al Choir, Fikaron, "Teori Dan Aplikasi Statistika Deskriptif Untuk Ekonomi Dan Bisnis", Rajagrafindo Persada, Jakarta, 2013.

Anwar, "Teori dan Praktek Kepemimpinan” Gramedia, Jakarta, 2012.

Arikunto, "Prosedur Penelitian: Suatu Pendekatan Praktek", Rineka Cipta,Jakarta, 2010.

Diana Prasetya Ningsih, "Pengaruh Gaya Kepemimpinan dan Disiplin Kerja Terhadap Kinerja Karywan pada PT. Target Prima Lestari", 
Universitas Pamulang,

Tangerang Selatan, 2016.

Elis Solihah, "Pengaruh Budaya Organisasi Terhadap Kinerja Karyawan di Kota Bunga Puncak", Indonesia School of Management, 2014.

Feriyanto, Andri dan Lindang Shyta

Triana, "Pengantar Manajemen (3 in 1)". Mediatera, Kebumen. 2015

Hasibuan, Malayu, "Manajemen Sumber Daya Manusia", PT. Bumi Aksara, Jakarta. 2011

Hendriawan,"Pengaruh Gaya Kepemimpinan dan Budaya Organisasi Terhadap Kinerja Karyawan pada PT. Dwi Mitra Multiguna Sejahterah di Konawe Utara", Universitas Hasanuddin Makasar, 2014.

Kartono, Kartini, "Pemimpin dan Kepemimpinan”. PT. Raja Grafindo Perkasa, Jakarta, 2014.

Mangkunegara, Anwar Prabu, "Sumber Daya Manusia Perusahaan", Cetakan kedua belas, Remaja Rosdakarya, Bandung, 2013

Mangkuprawira, "Manajemen Sumber Daya Manusia Strategik", Ghalia Indonesia, Jakarta 2013.

Notoatmojo, "Metodologi Penelitian Kesehatan". Rineka Cipta, Jakarta, 2015

Rivai, "Manajemen Sumber Daya Manusia untuk Perusahaan: Dari Perusahaan ke Praktik", Edisi Ke-1, Rajawali Pers, Jakarta. 2014.

Robbins, "Perilaku Organisasi", Salemba Empat, Jakarta, 2016
Samsudin, Sadili, "Manajemen Sumber Daya Manusia", Pustaka Setia, Bandung, 2010.

Santoso, Singgih, "Menguasai Statistik Multivariat", PT. Elex Media Komputindo, Jakarta, 2015.

Sedarmayanti, "Sumber Daya Manusia dan Produktivitas Kerja”, CV. Mandar Maju, Bandung, 2009.

Simamora, Henry, "Manajemen Sumber Daya Manusia". Bagian Penerbitan Sekolah Tinggi Ilmu Ekonomi YKPN, Yogyakarta, 2014.

Simanjutak, "Dimensi Ekonomi Perpajakan dalam Pembangunan Ekonomi", Penerbit Raih Asa Sukses. Bogor, 2012

Siswanto, H.B, "Manajemen Tenaga Kerja Indonesia Pendekatan Administratif dan Operasional", PT. Bumi Aksara, Jakarta. 2011.

Sugiyono, "Metode Penelitian Kuantitatif, Kualitatif, dan $R \& D$ ”, Alfabeta, Bandung. 2016.

Sunarsi, D. (2018). Pengaruh Gaya Kepemimpinan dan Disiplin Kerja Terhadap Kinerja Karyawan Pada CV. Usaha Mandiri Jakarta. JENIUS, 1(2).

Sutrisno, Edi, "Manajemen Sumber Daya Manusia", Prenademeia Group, Jakarta, 2016.

Wibowo, "Manajemen Kinerja", Edisi Kelima, PT. Rajagrafindo Persada, Jakarta, 2016

Widodo, Suparno Eko, "Manajemen Pengembangan Sumber Daya Manusia". Pustaka Pelajar, Yogyakarta. 2015. 
Wirawan, "Kepemimpinan, Teori,

Psikologi, Perilaku Organisasi,

Aplikasi dan Penelitian",

Rajagrafindo Persada, Jakarta

2014. 